\title{
Effects of JSOG-6 on protection against bone loss in ovariectomized mice through regulation of osteoblast differentiation and osteoclast formation
}

\author{
Hwa-Jin Chung ${ }^{1}$, Lan Cho', Joon-Shik Shin², Jinho Lee², In-Hyuk Ha², Hyen Joo Park ${ }^{1}$ and Sang Kook Lee ${ }^{\text {** }}$
}

\begin{abstract}
Background: JSOG-6 is used as a traditional medicine to relieve the symptoms associated with inflammation, rheumatism, and osteoporosis in Korea. In the present study, we investigated the effects of JSOG-6 on bone loss prevention both in in vitro and in vivo as well as its underlying mechanism of action.

Methods: Protection against bone loss was assessed in an ovariectomized (OVX) mouse model. Bone microarchitecture was measured using a micro-computed tomography to detect the parameters of three-dimensional structure of a trabecular bone. Serum biomarkers were also evaluated in an OVX-induced model. Osteoclasts derived from mouse bone marrow cells (BMCs) and osteoblastic MC3T3-E1 cells were also employed to investigate the mechanism of action.
\end{abstract}

Results: Oral administration of JSOG-6 significantly increased the bone mineral density (BMD) of the femur in OVX mice in vivo. Especially, the reduced Tb.No (trabecular bone number) in the OVX group was significantly recovered by JSOG-6 treatment. The serum levels of alkaline phosphatase (ALP), osteocalcin, C-terminal telopeptide, and tartrate-resistant acid phosphatase, biomarkers of bone resorption, were significantly elevated in OVX mice, but JSOG-6 effectively inhibited the increase in OVX mice. JSOG-6 was also found to enhance the osteoblastic differentiation and maturation with the increase of the density and ALP activity, a marker of osteoblastic differentiation, as well as calcium deposition, a marker of osteoblastic maturation in MC3T3-E1 cells. The effects of JSOG-6 on osteoblastic differentiation were also associated in part with the increase of ALP and OPN mRNA expressions and the decrease of RANKL mRNA expression in MC3T3-E1 cells.

Conclusions: The findings demonstrate that JSOG-6 induced protection against bone loss in OVX mice, and its anti-osteoporotic property might be, in part, a function of the stimulation of osteoblast differentiation and the inhibition of osteoclast formation. These findings suggest that JSOG-6 might be an applicable therapeutic traditional medicine for the regulation of the osteoporotic response.

Keywords: JSOG-6, Ovariectomized mice, Bone loss, Osteoclast, Osteoblast

\section{Background}

Osteoporosis is an age-dependent metabolic bone disease characterized by the decrease in bone mass, the deterioration of bone tissue, and an increased risk of fractures $[1,2]$. In the process of osteoporosis, the bone mineral density (BMD) is decreased, bone microarchitecture is deteriorated, and a variety of proteins in bone are also

\footnotetext{
* Correspondence: sklee61@snu.ac.kr

${ }^{1}$ College of Pharmacy, Natural Products Research Institute, Seoul National University, San 56-1 Sillim-dong, Gwanak-gu, Seoul 151-742, Korea

Full list of author information is available at the end of the article
}

altered. Bone mass is regulated by continuous bone remodeling through bone resorption and bone formation by osteoclasts and osteoblasts, respectively [3,4]. Indeed, bone homeostasis depends on maintaining a balance between the activities of bone-forming osteoblasts and boneresorbing osteoclasts $[5,6]$, which is ultimately determined by the proliferation and differentiation of progenitors of these two bone-associated cells.

Osteoclasts are derived from hematopoietic cells within the monocyte/macrophage lineage [7] and regulated by the 
combined action of the receptor activator of the NF- $\mathrm{kB}$ ligand (RANKL) [8]. However, osteoblasts induce the increase in bone mass by inhibiting the ability of osteoclasts. Osteoblasts also express RANKL and osteoprotegerin (OPG), a decoy receptor of RANKL, which are essential factors regulating the formation and activation of osteoclasts (osteoclastogenesis) $[9,10]$. Therefore, the balance of RANKL and OPG mainly contributes to bone remodeling because RANKL stimulates osteoclastogenesis, while OPG suppresses bone resorption [11]. Yet, excessive osteoclastogenesis and defects in osteoblastogenesis are associated with bone diseases such as osteoporosis and rheumatoid arthritis [12].

JSOG-6 (named Bogangyeongol-hwan) consists of a mixture of six crude drugs, and each drug has been widely used in traditional medicine to treat various bone disorders such as arthritis, degenerative disc disease and osteoporosis. Of the six components of JSOG-6, Harpagophytum procumbens var. sublobatum (Engl.) Stapf, radix, called Devil's claw, is an herbal substance commonly used by patients with osteoarthritis (OA). Anti-inflammatory activities of the root extracts of $H$. procumbens var. sublobatum have also been reported in various inflammation models [13-15]. Another component of JSOG-6, Drynaria fortunei (Kunze ex Mett.) J. Sm., rhizome also showed an anti-osteogenic effect in a bone-resorption model [16] as well as anti-inflammatory properties [17]. Poria cocos F.A.Wolf, sclerotium [18] and Rehmannia glutinosa (Gaertn.) DC., radix [19] exhibited anti-inflammatory effects. Furthermore, Panax ginseng C.A.Mey., radix showed an anti-osteoporotic effect in an OVX rat model [20]. These reported data suggest that JSOG-6 might have the potential to alleviate the symptoms of bone loss-associated diseases.

In the present study, we investigated the activities of JSOG-6 in vitro and in in vivo bone-remodeling models and examined its underlying molecular mechanism.

\section{Methods}

\section{Preparation of test samples}

A mixture of six crude drugs (Harpagophytum procumbens var. sublobatum (Engl.) Stapf, radix (120 g), Drynaria fortunei (Kunze ex Mett.) J. Sm., rhizome (120 g), Equus asinus L., gelatinized (120 g), Poria cocos F.A.Wolf, sclerotium (120 g), Rehmannia glutinosa (Gaertn.) DC., radix (120 g), and Panax ginseng C.A.Mey., radix (120 g)) was boiled in tap water $(10 \mathrm{~L})$ for $6 \mathrm{~h}$, and the extract was freeze-dried to obtain the JSOG-6 extracts (259 g, 35.6\%). The crude drugs were purchased from an herbal market in Seoul, Korea, and authenticated by Dr. S.H. Lee, Jaseng Hospital of Korean Medicine in Seoul, Korea. Voucher specimens of the plants used in this study were deposited in the herbarium at Jaseng Hospital of Oriental Medicine.

\section{Animals}

Female ICR mice (18-20 g, 8 weeks old) were purchased from Central Laboratory Animal Inc. (Seoul, Korea). Animals were housed under standard laboratory conditions with free access to food and water. The temperature was thermostatically regulated to $22^{\circ} \mathrm{C} \pm 2^{\circ} \mathrm{C}$, and a 12-hour light/dark schedule was maintained. Prior to their use, they were allowed one week for acclimatization within the work area environment. All animal experiments were carried out in accordance with the Institutional Animal Care and Use Committee Guidelines of Ewha Womans University (permission number: EWHA2010-2-07).

At 9 weeks of age, mice were bilaterally OVX, and 8 mice were Sham-operated (Sham). After 1 week of recovery from surgery, the OVX mice were randomly divided into 5 groups of 8 mice per group (OVX control, 17 $\beta$-estradiol (E2, $20 \mu \mathrm{g} / \mathrm{kg})$, and JSOG-6 (50, 150, or $450 \mathrm{mg} / \mathrm{kg})$ ). JSOG-6 was orally administered in distilled water $(0.3 \mathrm{~mL})$ for 12 weeks, and the same volume of distilled water was used in the Sham- and OVX control groups. After 12 weeks of treatment, the animals were sacrificed, and blood samples were collected for serum isolation. The femur bones were dissected and divested of soft tissue for analysis of trabecular microarchitecture.

\section{Analysis of serum bone biomarkers}

Serum calcium (Ca) and phosphorus $(\mathrm{P})$ were measured as previously described [21]. The serum concentrations of osteocalcin (OCN) and alkaline phosphatase (ALP) activity were assayed using an ELISA kit (Biomedical Technologies Inc., Stoughton, MA, USA) and QuantiChrome ALP assay kit (DALP-250, BioAssay Systems, CA, USA) according to the manufacturer's instructions, respectively. The serum levels of C-terminal telopeptides (CTx), bone resorption biomarkers that indicate osteoclastic activity, were also analyzed using commercial ELISA kits (Serum CrossLaps, Nordic Bioscience, Herlev, Denmark). The tartrate-resistant acid phosphatase (TRAP) concentration was determined by a mouse TRAP assay kit (Suomen Bioanalytikka Oy, Turku, Finland).

\section{Analysis of bone microarchitecture}

Bone microarchitecture of the femur was scanned using a micro-computed tomography ( $\mu$ CT system, SkyScan 1076, Aart-selaar, Belgium) in the region of 0.6-2.1 mm from the growth plate. The X-ray source was set at a voltage of $50 \mathrm{kV}$ and a current of $200 \mu \mathrm{A}$ and filtered with a $0.5 \mathrm{~mm}$ aluminum filter. The scanning angular rotation was $180^{\circ}$ with an angular step of $0.5^{\circ}$. The voxel size was fixed at $8.9 \mu \mathrm{m}$. The morphometric index of the bone region was determined from the microtomographic data using a 3D image (SkyScan). The following measures characterizing the three-dimensional structure of a trabecular bone were determined: the ratio of bone components to volume of 
interest (BV/TV,\%), trabecular thickness (Tb.Th, mm), trabecular separation ( $\mathrm{Tb} . \mathrm{Sp}, \mathrm{mm}$ ), trabecular bone number (Tb.N, mm-1), and structure model index (SMI).

$\mathrm{BV} / \mathrm{TV}$ indicates the ratio which a trabecular bone is occupied with a given volume of interest, usually measured as a\% value. Tb.Th and Tb.Sp define the shape of a trabecular bone, whereas Tb.N implies the number of traversals made per unit length on a random linear path across a trabecular bone through a given volume of interest. SMI quantifies the relative prevalence of rod-, plate-, or sphere-shapes in a trabecular bone structure.

\section{Chemicals}

$\alpha$-Modified minimal essential medium ( $\alpha$-MEM), fetal bovine serum (FBS), sodium pyruvate, L-glutamine, antibioticantimycotic solution, and trypsin-EDTA were purchased from Invitrogen Co. (Grand Island, NY, USA). RANKL and macrophage-colony stimulating factor (M-CSF) were purchased from R\&D systems (Minneapolis, MN, USA). Ascorbic acid, $\beta$-glycerophosphate,3-(4,5-dimethylthiazol-2-yl)2,5-diphenyltetrazolium bromide (MTT), and other chemicals were obtained from Sigma (St. Louis, MO, USA) unless otherwise indicated.

\section{Cell culture}

Mouse calvaria MC3T3-E1 cells, obtained from American Type Culture Collection (ATCC, Rockville, MD, USA), were cultured in $\alpha$-MEM supplemented with $10 \%$ heatinactivated FBS, 100 units $/ \mathrm{mL}$ penicillin, $100 \mu \mathrm{g} / \mathrm{mL}$ streptomycin, and $0.25 \mu \mathrm{g} / \mathrm{mL}$ amphotericin B. Cells were incubated at $37^{\circ} \mathrm{C}$ and $5 \% \mathrm{CO}_{2}$ in a humidified atmosphere.

\section{Evaluation of growth inhibitory potential}

MC3T3-E1 cells $\left(1 \times 10^{4}\right.$ cells $/ \mathrm{mL}$ in 96 -well plates $)$ were treated with various concentrations of JSOG-6 and incubated at $37^{\circ} \mathrm{C}$ in a humidified atmosphere with $5 \% \mathrm{CO}_{2}$. After JSOG-6 treatment for $72 \mathrm{~h}$, MTT solution $(5 \mathrm{mg} / \mathrm{mL}$ in PBS) was added to the medium (final concentration $500 \mu \mathrm{g} / \mathrm{mL}$ ) and further incubated for $4 \mathrm{~h}$. The medium was discarded and $200 \mu \mathrm{L}$ of $(100 \%$ or $10 \%)$ DMSO was added to each well to dissolve the formazan. The absorbance was measured at $570 \mathrm{~nm}$. The effect of JSOG-6 on cell growth was calculated as a percentage relative to solvent-treated control incubations, and the $\mathrm{IC}_{50}$ values were calculated using non-linear regression analysis (percent cell proliferation versus concentration).

\section{Alkaline phosphatase (ALP) activity}

The ALP activity was determined according to a previously described method [22]. MC3T3-E1 cells were incubated in osteogenic medium containing $400 \mu \mathrm{M}$ ascorbic acid and $5 \mathrm{mM} \beta$-glycerophosphate. The cells $\left(2 \times 10^{4}\right.$ cells $\left./ \mathrm{mL}\right)$ were incubated with or without various concentrations of JSOG-6. After 4 days, the cells were washed with PBS and fixed with 70\% ethanol for $5 \mathrm{~min}$ and then extracted into lysis solution (10 mM Tris, $0.1 \%$ Triton X-100 buffer ( $\mathrm{pH} 7.5$ ). Enzyme activity was determined using $p$-nitrophenylphosphate $(p$-NPP) as a substrate. The color change reflecting the conversion of $p$ NPP to $p$-nitrophenol was measured at $405 \mathrm{~nm}$. The protein concentration of cell lysates was measured using the Bradford assay.

\section{Mineralization assay}

The calcium deposition of MC3T3-E1 cells was determined by a previously reported method [23]. MC3T3E1 cells $\left(2 \times 10^{4}\right.$ cells $\left./ \mathrm{mL}\right)$ were incubated with or without various concentrations of JSOG-6 for 14 days. The cells were washed twice with PBS and fixed with $70 \%$ ethanol for $30 \mathrm{~min}$. The fixed MC3T3-E1 cells were stained with $2 \%$ Alizarin Red S solution ( $\mathrm{pH} 4.0$ ) for $5 \mathrm{~min}$. The plate was washed several times by distilled water, and then the cells were observed under a microscope.

\section{Real-time reverse transcriptase-polymerase chain reaction (Real-time RT-PCR)}

Lipopolysaccharide (LPS), a cell component of Gramnegative bacteria, is an important mediator of pathological bone destruction associated with inflammation. MC3T3E1 cells were stimulated with $1 \mu \mathrm{g} / \mathrm{mL}$ LPS in the presence or absence of JSOG-6 for $48 \mathrm{~h}$. Total cellular RNA was extracted with TRI reagent (Sigma, St. Louis, MO, USA) according to the manufacturer's recommended procedure. Total RNA $(1 \mu \mathrm{g})$ was reverse-transcribed using oligo-(dT) ${ }_{15}$ primers and avian myeloblastosis virus (AMV) reverse transcriptase (Promega, Madison, WI, USA).

Real-time RT-PCR was conducted with a MiniOpticon system (Bio-Rad, Hercules, CA, USA) using $5 \mu \mathrm{L}$ of the reverse-transcription product, $\mathrm{iQ}^{\mathrm{TM}} \mathrm{SYBR}^{\oplus}$ Green Supermix (Bio-Rad, Hercules, CA, USA) and primers for a total volume of $20 \mu \mathrm{L}$. Standard thermal cycler conditions were employed $\left(95^{\circ} \mathrm{C}\right.$ for $20 \mathrm{~s}, 40$ cycles of $95^{\circ} \mathrm{C}$ for $20 \mathrm{~s}, 56^{\circ} \mathrm{C}$ for $20 \mathrm{~s}$, and $72^{\circ} \mathrm{C}$ for $30 \mathrm{~s}$, followed by $95^{\circ} \mathrm{C}$ for $1 \mathrm{~min}$, and $55^{\circ} \mathrm{C}$ for $\left.1 \mathrm{~min}\right)$. The threshold cycle $\left(C_{\mathrm{T}}\right)$, the fractional cycle number at which the amount of amplified target gene reaches a fixed threshold, was determined by MJ Opticon Monitor software. The mean threshold cycle $\left(\mathrm{C}_{\mathrm{T}}\right)$ value for each transcript was normalized by dividing it by the mean $C_{T}$ value for the $\beta$-actin transcript for that sample. Normalized transcript levels were expressed relative to those obtained from the control. Real-time RT-PCR primer sequences are listed in Table 1. 
Table 1 Sequences of target gene-specific primers used in real-time PCR

\begin{tabular}{|c|c|c|c|}
\hline Target genes & & Sequences & Accession number \\
\hline \multirow{2}{*}{ ALP } & Sense & 5'-ATGCCCTGAAACTCCAAA-3' & \multirow{2}{*}{ NM_001287176 } \\
\hline & Antisense & 5'-AGACGCCCATACCATCTC-3' & \\
\hline \multirow{2}{*}{ OPN } & Sense & 5'-GCTTGGCTTATGGACTGA-3' & \multirow{2}{*}{ NM_001204201 } \\
\hline & Antisense & 5'-GGCAACAGGGATGACATC-3' & \\
\hline \multirow{2}{*}{$\mathrm{OCN}$} & Sense & 5'-CAGACAAGTCCCACACAG-3' & \multirow{2}{*}{ NM_007541 } \\
\hline & Antisense & 5'-GCAGAGTGAGCAGAAAGA-3' & \\
\hline \multirow{2}{*}{ OPG } & Sense & 5'-TGGGAGAAGAACCTTATTTTG-3' & \multirow{2}{*}{ NM_008764 } \\
\hline & Antisense & 5'-CCAGCATCCTCTITCATAAAG-3' & \\
\hline \multirow{2}{*}{ RANKL } & Sense & 5'-CCATGAAAACGCAGATTTG-3' & \multirow{2}{*}{ NM_011613 } \\
\hline & Antisense & 5'-CCCTGAAAGGCTTGTTTC-3' & \\
\hline \multirow{2}{*}{$\beta$-actin } & Sense & 5'-AAGGCCAACCGTGAAAAGAT-3' & \multirow{2}{*}{ NM_007393 } \\
\hline & Antisense & 5'-GTGGTACGACCAGAGGCATAC-3' & \\
\hline
\end{tabular}

\section{Preparation of total cell lysates}

MC3T3-E1 cells $\left(5 \times 10^{5}\right.$ cells $/ \mathrm{mL}$ in $60 \mathrm{~mm}$ dish $)$ were incubated with or without various concentrations of JSOG-6 for 48 h. To obtain total cell lysates, the cells were washed with ice-cold PBS and lysed in boiling $2 \mathrm{X}$ sample loading buffer (250 mM Tris- $\mathrm{HCl}$
(pH 6.8), 4\% SDS, 10\% glycerol, $0.006 \%$ bromophenol blue, $50 \mathrm{mM}$ sodium fluoride, $5 \mathrm{mM}$ sodium orthovanadate, and $2 \% \beta$-mercaptoethanol). Cell lysates were boiled for an additional $20 \mathrm{~min}$ and stored at $-20^{\circ} \mathrm{C}$. The protein content of cell lysates was determined by the BCA method.
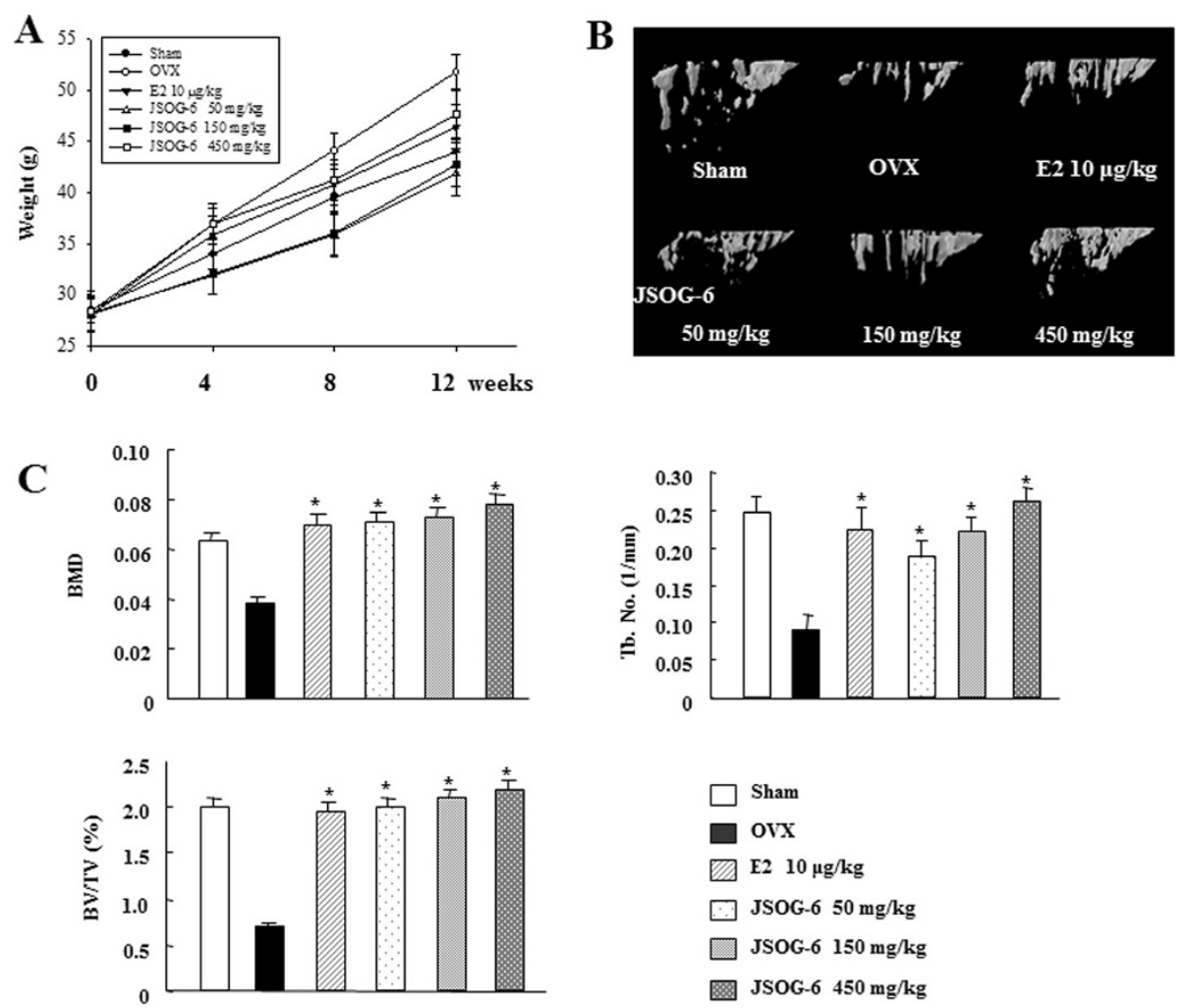

Figure 1 Effect of JSOG-6 on bone loss in OVX mice. (A) Change in body weight 12 weeks after ovarietomy. (B) Effect of JSOG-6 on bone 3D microCT image of the distal femur in OVX mice. (C) Effect of JSOG-6 on the bone morphometric parameters BMD, BV/TV (\%), and Tb.No (1/mm) as analyzed with micro-CT SkyScan CTAN software. Data represent the mean \pm S.D. $(n=8) .{ }^{*} P<0.01$ indicates statistically significant differences from the OVX mice group. 
Table 2 Effect of JSOG-6 on the serum parameters in OVX mice

\begin{tabular}{|c|c|c|c|c|c|c|}
\hline & Calcium concentration & Potassium concentration & ALP activity & TRAP activity & Osteocalcin level & CTx level \\
\hline Sham & $9.1 \pm 0.4$ & $8.0 \pm 0.3$ & $67.6 \pm 2.8$ & $9.1 \pm 0.9$ & $148.9 \pm 5.3$ & $69.5 \pm 4.3$ \\
\hline ovx & $9.3 \pm 0.3$ & $8.3 \pm 0.4$ & $85.0 \pm 3.1$ & $19.8 \pm 1.0$ & $176.9 \pm 4.7$ & $95.7 \pm 3.8$ \\
\hline E2 & $9.1 \pm 0.6$ & $7.9 \pm 0.2$ & $59.9 \pm 3.1^{*}$ & $10.8 \pm 1.0^{*}$ & $141.9 \pm 4.9^{*}$ & $76.6 \pm 4.7^{*}$ \\
\hline \multicolumn{7}{|l|}{ JSOG-6 } \\
\hline $50 \mathrm{mg} / \mathrm{kg}$ & $9.4 \pm 0.5$ & $7.9 \pm 0.3$ & $59.3 \pm 3.8^{*}$ & $11.6 \pm 1.4^{*}$ & $165.0 \pm 6.6$ & $92.3 \pm 3.6$ \\
\hline $150 \mathrm{mg} / \mathrm{kg}$ & $9.4 \pm 0.6$ & $7.9 \pm 0.3$ & $62.8 \pm 4.6^{*}$ & $9.7 \pm 1.1^{*}$ & $155.8 \pm 5.1^{*}$ & $89.7 \pm 5.2$ \\
\hline 450 mg/kg & $9.6 \pm 0.4$ & $8.1 \pm 0.4$ & $65.9 \pm 3.4^{*}$ & $8.3 \pm 0.7^{*}$ & $153.0 \pm 5.3^{*}$ & $83.6 \pm 3.8^{*}$ \\
\hline
\end{tabular}

The serum levels of calcium, potassium, ALP, CTx, OCN, and TARP were analyzed as described in the Methods. Data represent the mean \pm S.D. $(n=8) .{ }^{*} P<0.01$ indicates statistically significant differences from the OVX mice group.
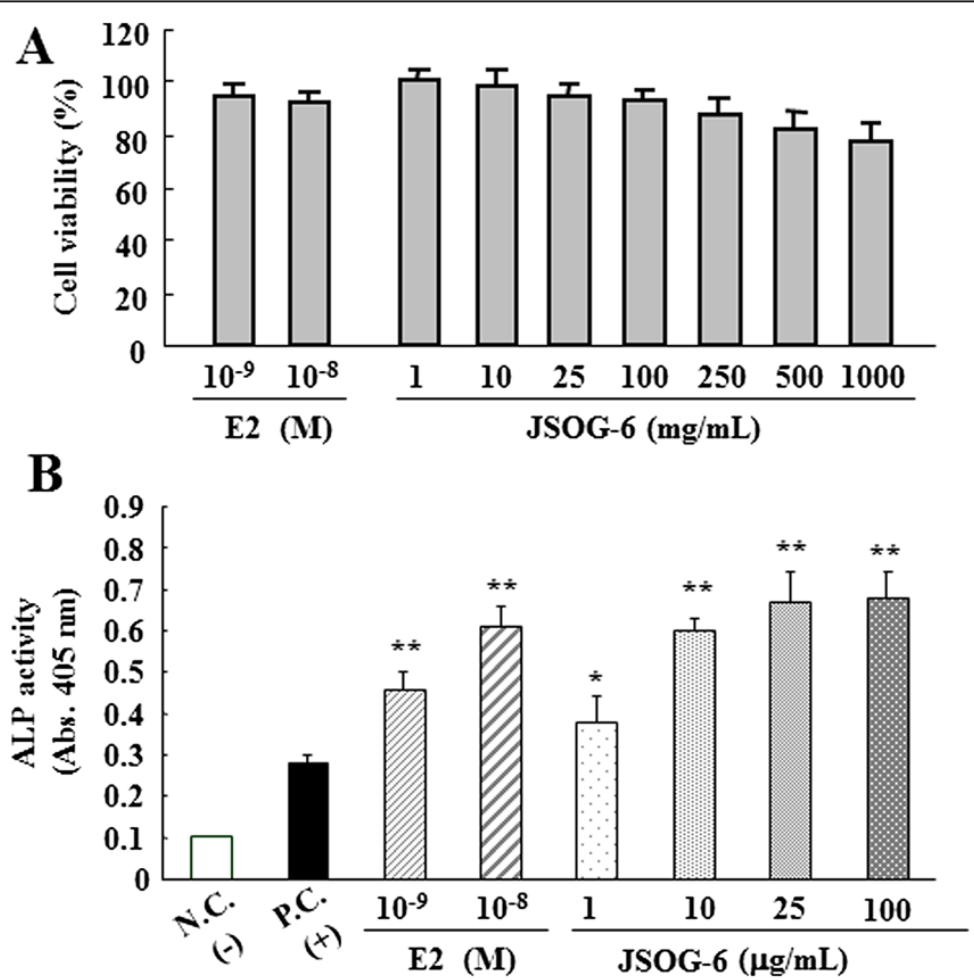

ALP staining

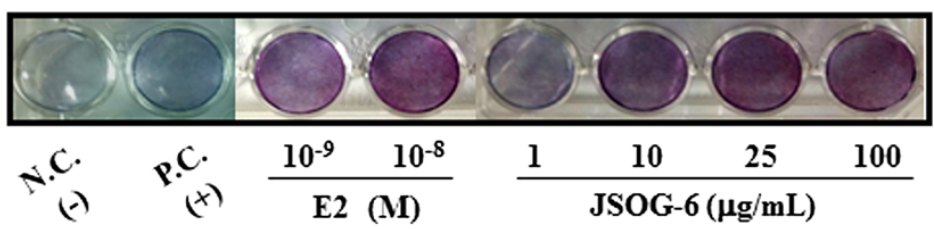

Figure 2 Effect of JSOG-6 on ALP activity in MC3T3-E1 cells. (A) Cell viability was measured by the MTT method as described in the Methods. (B) MC3T3-E1 cells $\left(2 \times 10^{4}\right.$ cells $\left./ \mathrm{mL}\right)$ were incubated with JSOG-6 in the presence of ascorbic acid and $\beta$-glycerophosphate for 4 days. The ALP activity was corrected for the amount of protein. Data represent the mean \pm S.D. $(n=3) .{ }^{*} P<0.05,{ }^{*} P<0.01$ indicates statistically significant differences from the control group. N.C., negative control; P.C., positive control (ascorbic acid + $\beta$-glycerophosphate). 


\section{Western blot analysis}

Equal amounts of cell lysates $(40 \sim 50 \mu \mathrm{g})$ were subjected to $8 \%$ and $10 \%$ SDS-PAGE and electrotransferred onto polyvinylidene difluoride (PVDF) membranes (Millipore, MA, USA). Membranes were blocked in PBST (PBS with $0.1 \%$ Tween-20) containing 5\% non-fat dry milk for $1 \mathrm{~h}$ at room temperature. After washing 3 times with PBST, membranes were incubated with primary antibodies against OPG, RANKL, c-Fos, and TRAF6 (Santa Cruz Biotechnology, Santa Cruz, CA, USA), p-ERK, ERK (Cell Signaling, Danvers, MA, USA), and $\beta$-actin (Sigma) for $3 \mathrm{~h}$ at room temperature or overnight at $4^{\circ} \mathrm{C}$. Membranes were washed 3 times with PBST and incubated with the corresponding secondary antibodies (Santa Cruz) for $90 \mathrm{~min}$ at room temperature. The blots were washed 3 times with PBST and visualized using an enhanced chemiluminescence (ECL) Western blotting detection system (Lab Frontier, Suwon, Korea).

\section{Murine bone marrow-derived osteoclasts}

BMCs were isolated from 4-week-old mice as previously described [24]. The cells were plated into 96-well plates in $30 \mathrm{ng} / \mathrm{mL}$ of M-CSF for $24 \mathrm{~h}$. Next, the cells were treated with the indicated concentrations of JSOG-6 in the presence of $100 \mathrm{ng} / \mathrm{mL}$ of RANKL and $30 \mathrm{ng} / \mathrm{mL}$ of
M-CSF. The medium was replaced with $50 \%$ volume with and without JSOG-6 every 2 days, and the culture was terminated after 5 days.

\section{Tartrate-resistant acid phosphatase (TRAP) staining}

Osteoclast differentiation was assessed by TRAP (SigmaAldrich, St. Louis, MO, USA) activity. 5 days after stimulating the cells with M-CSF and RANKL (100 and $30 \mathrm{ng} / \mathrm{mL}$, respectively), the cells were washed with $\mathrm{PBS}$ and fixed with $4 \%$ paraformaldehyde for $5 \mathrm{~min}$. The cells were rinsed in de-ionized water and incubated in tartrate-staining solution in the dark for $1 \mathrm{~h}$ at $37^{\circ} \mathrm{C}$. The cells were rinsed in deionized water and allowed to air dry. TRAP-positive multinucleated cells containing 3 or more nuclei were counted as osteoclasts.

\section{Statistics}

All experiments were repeated at least 3 times. Data are presented as the mean \pm SD for the indicated number of independently performed experiments. The statistical significance within a parameter was evaluated by one-way analysis of variation (ANOVA) coupled with Dunnett's $t$-test.

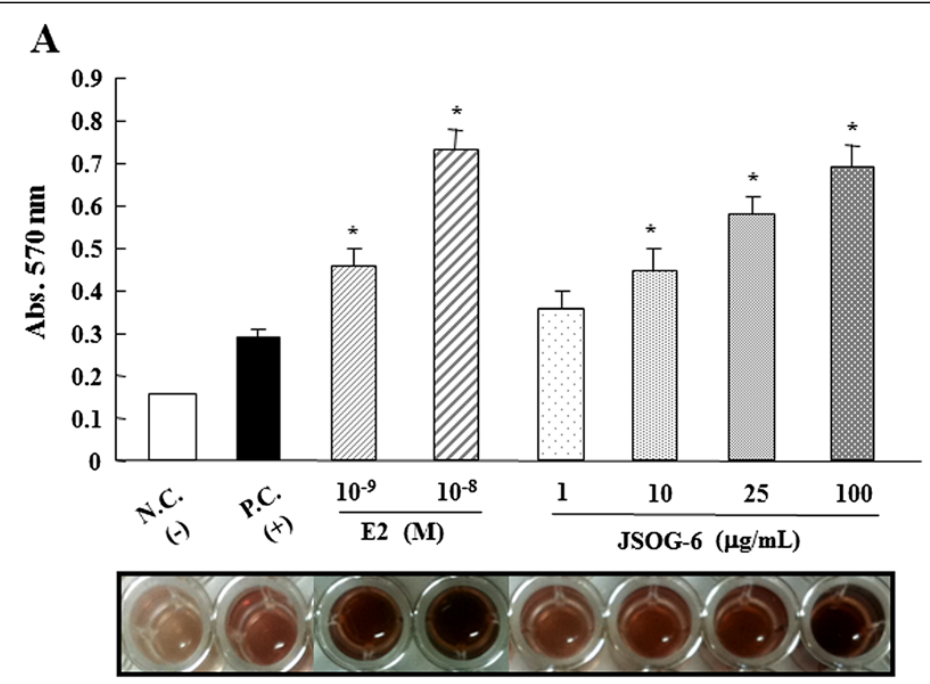

B
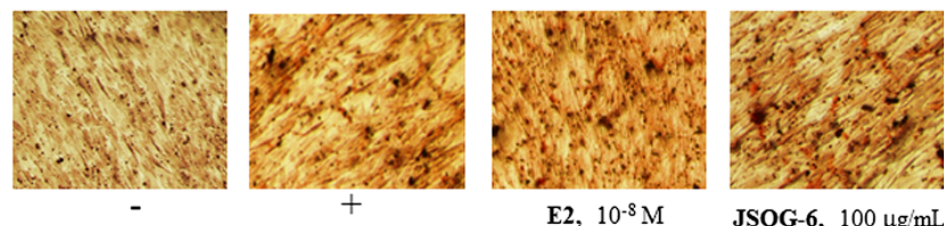

JSOG-6, $100 \mu \mathrm{g} / \mathrm{mL}$

Figure 3 Effect of JSOG- 6 on the mineralization of MC3T3-E1 cells. (A) MC3T3-E1 cells $\left(2 \times 10^{4}\right.$ cells/mL) were incubated with JSOG-6 in the presence of ascorbic acid and $\beta$-glycerophosphate for 14 days. Mineralized nodule formation was assessed by Alizarin red $\mathbf{S}$ staining. Data represent the mean \pm S.D. $(n=3) .{ }^{*} P<0.01$ indicates statistically significant differences from the control group. (B) Representative microscopic observation of JSOG-6 on the formation of calcification nodules with staining Alizarin red S. N.C., negative control; P.C., positive control (ascorbic acid + $\beta$-glycerophosphate). 


\section{Results}

\section{Effect of JSOG-6 on bone loss in an OVX-induced} mouse model

The anti-osteoporotic activity of JSOG- 6 was primarily performed in an in vivo experiment employing an OVXinduced bone loss mouse model. Body weight change was monitored during the administration of JSOG-6. As shown in Figure 1A, the increase in body weight in the OVX group was significantly higher than that in the Shamoperation group $(P<0.01)$. However, mice given an oral administration of JSOG-6 for 12 weeks after OVX showed a relatively slow increase in body weight compared to the OVX group. The estradiol (E2, $10 \mu \mathrm{g} / \mathrm{kg}$ )-treated group showed a similar result. The destruction of the trabecular bone of the femur was also observed by $3 \mathrm{D}-\mu \mathrm{CT}$. As illustrated in Figure 1B, OVX caused a significant deterioration of trabecular bone architecture compared with the Shamcontrol group $(P<0.01)$. However, treatment with JSOG-6 retarded or recovered the destruction of the trabecular bone of the femur in a dose-dependent manner in the OVX-induced bone loss model. The protective effect on trabecular bone microarchitecture was also clearly demonstrated by treatment with E2, a positive control, in the same experimental condition. In addition, the microstructural index parameters were observed in the OVX-induced bone loss model (Figure 1C). The BMD of the OVX group was markedly reduced by $38.7 \%$ in comparison with the Sham group. The BMD of the trabecular bone of the femur in mice treated with JSOG-6 (50 $\mathrm{mg} / \mathrm{kg}$ ) was shown to be $83.0 \%$ higher than that in the OVX group and was not significantly different from that in the Sham control group $(P<0.01)$. E2 also increased the BMD by $80.9 \%$ in the OVX-induced bone loss mouse model. The BV/TV was also markedly reduced in the OVX group (64.7\%) compared with the Sham group, but the treatment of OVX mice with JSOG-6 or E2 resulted in a significant increase in the $\mathrm{BV} / \mathrm{TV}$ in the OVX-induced bone loss model $(P<0.01)$. The Tb.No in the OVX group was $63.8 \%$ lower than that of the Sham group, but JSOG-6 treatment $(50,150$, and $450 \mathrm{mg} / \mathrm{kg}$ ) significantly recovered the Tb.No value to $113.3,145.6$, and $192.2 \%$, respectively, in a dose-dependent manner than the OVX group. The E2-treated group also showed a $150 \%$ recovery of $\mathrm{Tb}$.No compared to the OVX group.

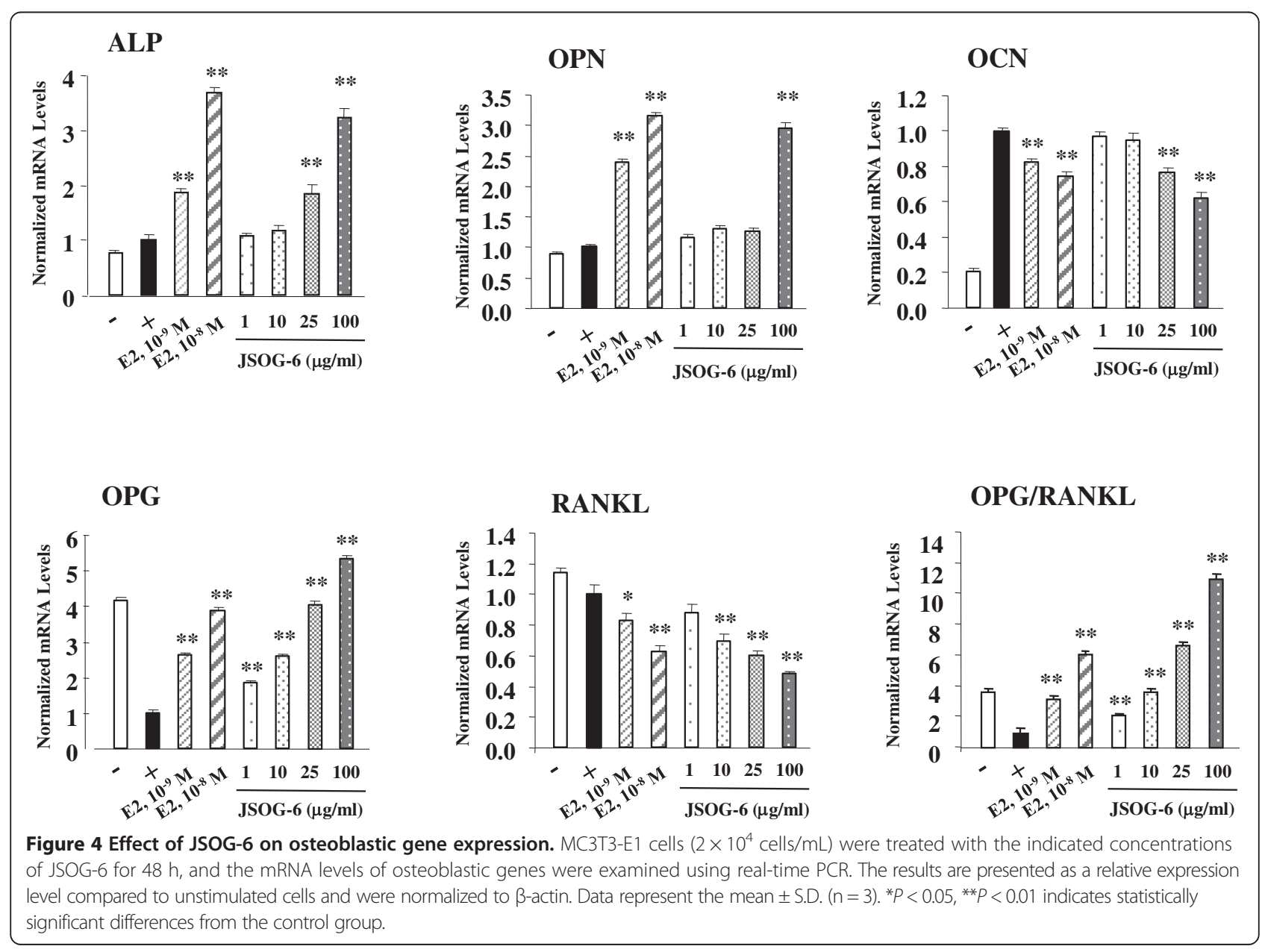




\section{Effect of JSOG-6 on serum biochemical markers in the OVX mouse model}

The effects of JSOG-6 on the bone metabolic biomarkers were also determined with the serum of blood samples collected in OVX mice. The serum levels of calcium and potassium were not significantly different in the Sham, JSOG-6 treatment, and OVX groups $(P<$ 0.01) (Table 2). The serum levels of the bone formation markers ALP and OCN were significantly increased in the OVX group compared to the Sham group. However, JSOG-6 treatment decreased the elevated serum levels of ALP and OCN in the OVX mice $(P<0.01)$. In addition, the serum level of TRAP, which is responsible for enhanced osteoclastogenesis and activation of mature osteoclasts for bone resorption, was increased in the OVX group, but JSOG-6 treatment significantly reduced TRAP activity in a dose-dependent manner $(P<0.01)$. The increase in an additional bone resorption marker, CTx, in the OVX group was also inhibited by JSOG-6 treatment $(P<0.01)$ (Table 2$)$.

\section{Effect of JSOG-6 on the ALP activity of MC3T3-E1 cells}

The ALP staining activity, a marker of osteoblastic differentiation [25,26], was evaluated in osteoblastic MC3T3-El cells. There was no effect on MC3T3-El cell viability with JSOG-6 treatment up to $100 \mu \mathrm{g} / \mathrm{mL}$ as determined by the MTT assay ( $>95 \%$ cell viability) (Figure $2 \mathrm{~A}$ ). Therefore, the cells were treated with up to $100 \mu \mathrm{g} / \mathrm{mL}$ JSOG-6 to understand the biological effects of JSOG-6 without causing cytotoxicity. The MC3T3-El cells were differentiated in the presence of ascorbic acid and $\beta$-glycerophosphate in the cell culture medium. After 4 days of differentiation, JSOG- 6 was found to enhance the density and ALP activity in a concentration-dependent manner (Figure 2B).

\section{Effect of JSOG-6 on the mineralization of MC3T3-E1 cells}

Extracellular matrix mineralization is one of the markers of osteoblastic maturation. Alizarins red S staining was used to evaluate extracellular matrix calcium deposition. As illustrated in Figure 3, when the cells were simultaneously treated with JSOG-6 for 14 days, the calcification nodules, represented in red, in MC3T3-E1 cells were increased in a concentration-dependent manner. These results indicate that the effect of JSOG-6 on the ALP activity and calcium deposition stimulated osteoblast differentiation.

\section{Effect of JSOG-6 on osteoblastic gene expression}

The effects of JSOG- 6 on osteoblast differentiation was further elucidated using the analysis of expression of osteogenic differentiation mediators mRNA by real-time RTPCR. After 2 days of differentiation, JSOG-6 $(100 \mu \mathrm{g} / \mathrm{mL})$ caused a significant $(P<0.01)$ increase in the expressions of ALP and OPN mRNA, whereas the expression of OCN mRNA was decreased by JSOG-6 treatment. OPG and
RANKL play important roles in the maintenance of bone mass and the regulation of bone remodeling. The OPG/ RANKL ratio is the major index of osteoclastogenic stimulation. JSOG-6 treatment induced the expression of OPG mRNA in a concentration-dependent manner, whereas JSOG-6 significantly suppressed the expression of RANKL mRNA ( $\left.{ }^{*} P<0.05,{ }^{* *} P<0.01\right)$. In addition, JSOG-6 significantly increased the OPG/RANKL ratio in MC3T3-E1 cells $\left({ }^{*} P<0.01\right)$ (Figure 4). These findings suggest that JSOG-6 might modulate the process of osteoclastogenesis via its effect on the OPG/RANKL gene expressions.

Effect of JSOG-6 on the protein levels of OPG, RANKL, and ERK in MC3T3-E1 cells

The effect of JSOG-6 on the protein expressions of OPG, RANKL, and ERK in MC3T3-E1 cells was evaluated to confirm the activity of JSOG-6 on osteogenic differentiation. As shown in Figure 5A, JSOG-6 increased the protein expression of OPG in a concentration-dependent manner, but the protein expression of RANKL was suppressed. In addition, JSOG-6 treatment induced ERK phosphorylation (Figure 5B).

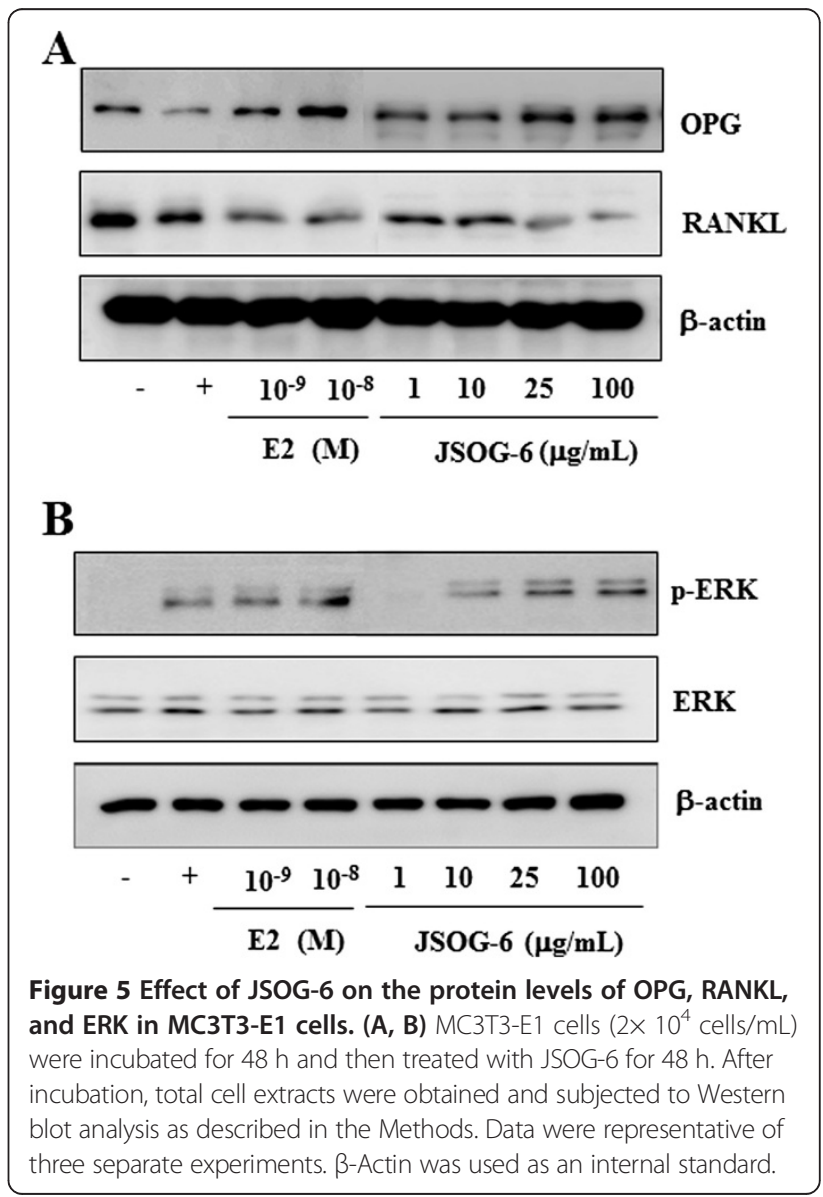




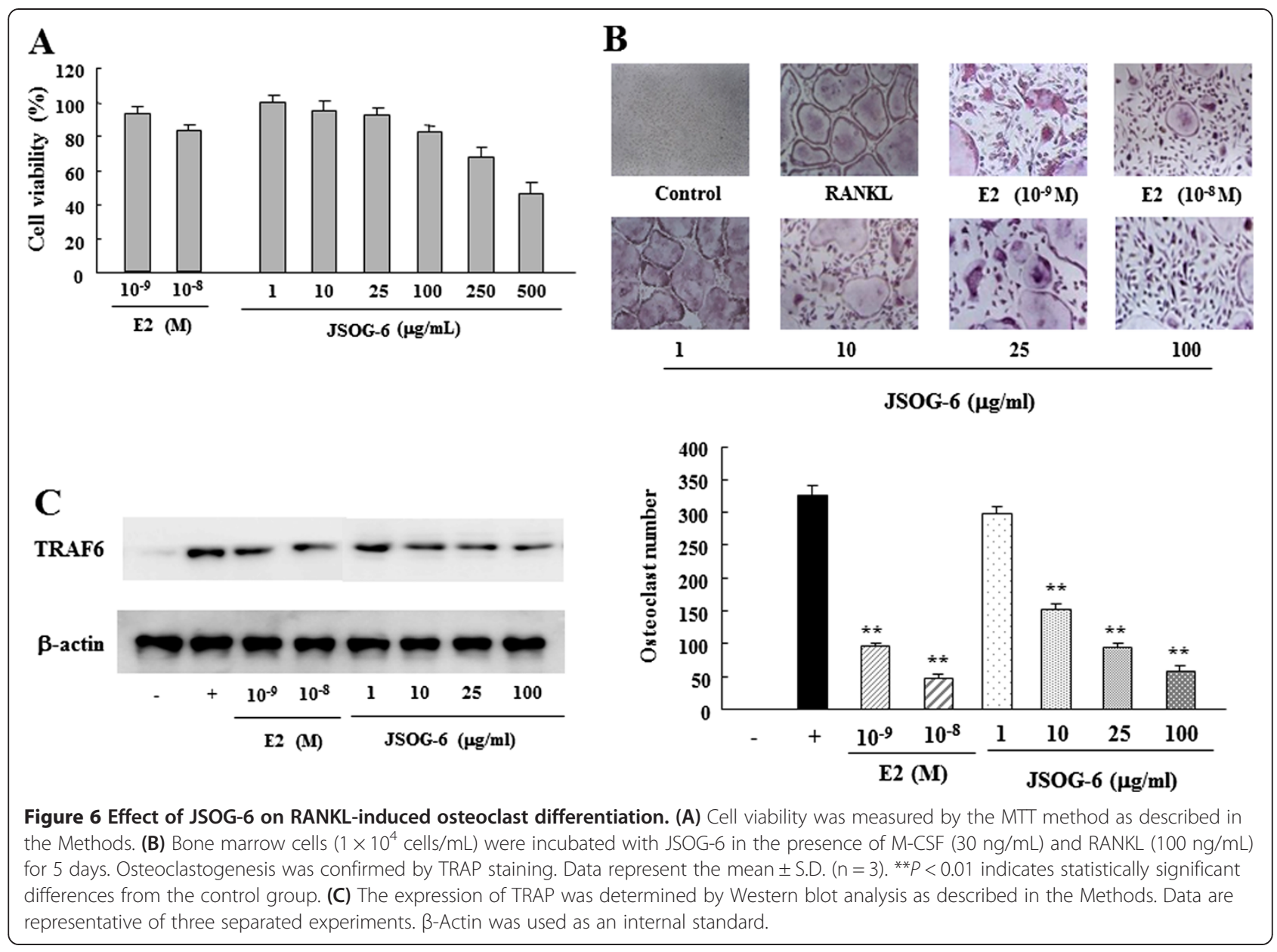

\section{Effect of JSOG-6 on osteoclast differentiation}

TRAP staining was performed to evaluate the effect of JSOG-6 on RANKL-induced osteoclast differentiation. As depicted in Figure 6A, no cytotoxic effect on BMCs was observed at a test concentration up to $100 \mu \mathrm{g} / \mathrm{mL}$ JSOG- 6 as determined by the MTT assay ( $>85 \%$ cell survival rate). $\mathrm{BMCs}$ were allowed to differentiate into osteoclasts in the presence of RANKL and M-CSF for 5 days. JSOG-6 inhibited the formation of TRAP-positive cells during RANKL-induced osteoclast differentiation in a concentrationdependent manner (Figure 6B). Western blot analysis showed that JSOG-6 also suppressed the protein expression of TRAF6 in RANKL-stimulated cells (Figure 6C).

\section{Discussion}

Osteoporosis is an age-dependent skeletal metabolic disease in which patients suffer from lower bone density and lower bone mass compared to healthy individuals $[27,28]$. The disease is also associated with a homeostatic imbalance between bone modeling and bone resorption. Although the main cause of the disease is not clear, endocrinologic, nutritional, and genetic factors are thought to be highly involved in osteoporosis.
JSOG-6 is an herbal preparation derived from six traditional medicines that have been clinically used to treat inflammation-associated diseases in oriental Korean medicine. However, the exact pharmacological effect and its underlying mechanisms of action remain to be elucidated. Therefore, the present study was performed to investigate the anti-osteoporotic activity of JSOG-6 in an OVX mouse model and to further elucidate its underlying mechanisms of actions both in vitro and in vivo.

The OVX animal model has been widely used to study postmenopausal osteoporosis mimicked by estrogen insufficiency $[29,30]$. Deterioration of trabecular 3D microarchitecture is apparent in the OVX mouse model [31]. We found that JSOG-6 prevented the deterioration of microstructural parameters in the distal femur in mice. Oral administration of JSOG- 6 restored bone loss back in OVX mice (Figure 1). These results indicated that JSOG-6 was effective not only in preserving bone mass but also in rescuing the deterioration of bone microarchitecture associated with OVX mice.

Biochemical markers of bone turnover have been determined previously, allowing the evaluation of the status of bone remodeling [32]. Analyses of the serum levels of ALP 
and OCN, typical biomarkers of osteoblastic activity, and CTx and TRAP, biomarkers of bone resorption, showed that the serum concentrations of ALP, OCN, CTx and TRAP in OVX mice were significantly higher than those in the Sham group. However, the levels of ALP and TRAP in the JSOG-6-treated group were equivalent to the levels in the Sham group (Table 2). These data suggest that JSOG-6 most likely prevents bone loss through decreased bone turnover.

In addition, the mechanisms underlying the cellular effects of JSOG-6 were investigated in osteoblasts and osteoclasts. Osteoblasts, bone-forming cells, synthesize and regulate the deposition and mineralization of the extracellular matrix of bone [33,34]. In this study, JSOG-6 treatment was found to increase the ALP activity in a concentrationdependent manner in MC3T3-E1 cells (Figure 2). JSOG-6 also led to an increase of calcium deposition in MC3T3- E1 cells (Figure 3).

To further explore the mechanism responsible for the effect of JSOG-6 on the regulation of osteoblasts, the markers of bone formation in MC3T3-E1 cells were detected by real-time RT-PCR. LPS leads to the intracellular induction of p38, JNK phosphorylation, and NFKB in macrophages and monocytes, and promotes the differentiation and survival of osteoclasts through the production of several factors such as PGE2, interleukin 1, RANKL, and TNF [35]. The levels of the bone formation biomarkers ALP, OPN, and OPG/RANKL mRNAs were up-regulated by JSOG-6 treatment (Figure 4).

RANKL drives osteoclastogenesis by providing an important signal to osteoclast progenitors through the membrane-anchored receptor RANK in osteoclasts. Osteoblasts also synthesize and secrete OPG, a decoy receptor of RANKL, which blocks the interaction between RANKL and RANK. Therefore, the expression of OPG/RANKL plays an essential role in modulating bone remodeling [36,37]. OPG was also able to block the interaction of RANKL with osteoclast cells, thus suppressing osteoclastogenesis [38]. The data showed that JSOG-6 up-regulated the protein expression of OPG and down-regulated that of RANKL (Figure 5A). Therefore, the suppression of the protein expressions of OPG and RANKL by JSOG-6 might be a plausible partial mechanism of action of its modulation of bone remodeling.

Various intracellular signaling pathways are involved in the regulation of osteoblast differentiation. ERK is considered to be an essential function in the proliferation and differentiation of osteoblasts [39,40]. In this study, JSOG-6 treatment induced the activation of ERK (Figure 5). These findings also suggest that JSOG-6 might have potential in improving bone formation.

Bone formation is regulated by crosstalk between boneforming osteoblasts and bone-resorbing osteoclasts. Unbalanced osteoclastogenesis causes bone loss in osteoporosis
[41,42]. M-CSF and RANKL are important cytokines that cause osteoclast precursors to differentiate into activated osteoclasts [43]. The present study showed that JSOG-6 suppressed RANKL-induced differentiation of osteoclasts by down-regulating the protein expression of TRAF6 in BMCs (Figure 6). These in vitro findings were well correlated with the in vivo anti-osteoporotic effects of JSOG-6, and thus JSOG-6 might be applicable to the clinic for improving age-dependent bone destruction disease.

\section{Conclusions}

The present study provides evidence that JSOG-6 has a potential anti-osteoporotic activity both in vitro and in vivo. The underlying mechanisms of action of JSOG-6 are correlated with the induction of ALP activation in osteoblasts, the increase in calcified bone matrix, and the reduction of osteoclast formation. These data provide a pharmacological basis for the use of JSOG-6 as a potential therapeutic strategy for protecting against osteoporotic bone loss in clinic.

\section{Competing interests}

The authors declare that they have no competing interest.

\section{Authors' contributions}

Conceived and designed the experiments: HJC, LC, and SKL. Performed the experiments HJC and LC. Analyzed the data: HJC, LC, and SKL. Contributed reagents, materials and analysis tools: HJC, LC, JSS, JL, IHH, and SKL. Wrote the paper: HJC, HJP, and SKL. Editing the paper: HJC, HJP, and SKL. All authors read and approved the final manuscript.

\section{Acknowledgments}

This work was supported by a grant from the JASENG Hospital of Korean Medicine (JS-2010-1).

\section{Author details}

${ }^{1}$ College of Pharmacy, Natural Products Research Institute, Seoul National University, San 56-1 Sillim-dong, Gwanak-gu, Seoul 151-742, Korea. ${ }^{2}$ Jaseng Spine and Joint Research Institute, Jaseng Medical Foundation, Jaseng Hospital of Korean Medicine, Seoul 135-896, Korea.

\section{Received: 13 December 2013 Accepted: 29 May 2014}

Published: 6 June 2014

\section{References}

1. Alexander JM, Bab I, Fish S, Müller R, Uchiyama T, Gronowicz G, Nahounou M, Zhao Q, White DW, Chorev M, Gazit D, Rosenblatt M: Human parathyroid hormone 1-34 reverses bone loss in ovariectomized mice. J Bone Miner Res 2001, 161:665-673.

2. Raisz LG: Pathogenesis of osteoporosis: concepts, conflicts, and prospects. J Clin Invest 2005, 115:3318-3325.

3. Takayanagi $\mathrm{H}$ : Inflammatory bone destruction and osteoimmunology. J Periodontal Res 2005, 40:287-293.

4. Papachroni KK, Karatzas DN, Papavassiliou KA, Basdra EK, Papavassiliou AG: Mechanotransduction in osteoblast regulation and bone disease. Trends Mol Med 2009, 15:208-216.

5. Harada S, Rodan GA: Control of osteoblast function and regulation of bone mass. Nature 2003, 15:349-355.

6. Rahman MM, Bhattacharya A, Fernandes G: Conjugated linoleic acid inhibits osteoclast differentiation of RAW264.7 cells by modulating RANKL signaling. J Lipid Res 2006, 47:1739-1748.

7. Rodan GA, Martin TJ: Therapeutic approaches to bone diseases. Science 2000, 289:1508-1514.

8. Suda T, Takahashi N, Udagawa N, Jimi E, Gillespie MT, Martin TJ: Modulation of osteoclast differentiation and function by the new members of the 
tumor necrosis factor receptor and ligand families. Endocr Rev 1999, 20:345-357.

9. Teitelbaum SL: Bone resorption by osteoclasts. Science 2000, 289:1504-1508.

10. Boyle WJ, Simonet WS, Lacey DL: Osteoclast differentiation and activation. Nature 2003, 423:337-342.

11. Martin TJ: Historically significant events in the discovery of RANK/RANKL/ OPG. World J Orthop 2013, 4:186-197.

12. Hadjidakis DJ, Androulakis II: Bone remodeling. Ann N Y Acad Sci 2006, 1092:385-396.

13. Inaba K, Murata K, Naruto S, Matsuda H: Inhibitory effects of devil's claw (secondary root of Harpagophytum procumbens) extract and harpagoside on cytokine production in mouse macrophages. J Nat Med 2012, 64:219-222.

14. Sanders M, Grundmann O: The use of glucosamine, devil's claw (Harpagophytum procumbens), and acupuncture as complementary and alternative treatments for osteoarthritis. Altern Med Rev 2011, 16:228-238.

15. Fiebich BL, Muñoz E, Rose T, Weiss G, McGregor GP: Molecular targets of the antiinflammatory Harpagophytum procumbens (devil's claw): inhibition of TNFa and COX-2 gene expression by preventing activation of AP-1. Phytother Res 2012, 26:806-811.

16. Chen LL, Lei LH, Ding PH, Tang Q, Wu YM: Osteogenic effect of Drynariae rhizoma extracts and Naringin on MC3T3-E1 cells and an induced rat alveolar bone resorption model. Arch Oral Biol 2011, 56:1655-1662.

17. Anuja GI, Latha PG, Suja SR, Shyamal S, Shine VJ, Sini S, Pradeep S, Shikha P. Rajasekharan S. Anti-inflammatory and analgesic properties of Drynaria quercifolia (L.) J. Smith. J Ethnopharmacol 2010, 11:456-460.

18. Nukaya $H$, Yamashiro $H$, Fukazawa $H$, Ishida $H$, Tsuji $K$ : Isolation of inhibitors of TPA-induced mouse ear edema from Hoelen, Poria cocos. Chem Pharm Bull 1996, 44:847-849.

19. Han Y, Jung HW, Lee JY, Kim JS, Kang SS, Kim YS, Park YK: 2,5dihydroxyacetophenone isolated from Rehmanniae Radix Preparata inhibits inflammatory responses in lipopolysaccharide-stimulated RAW264.7 macrophages. J Med Food 2012, 15:505-510.

20. Kim HR, Cui Y, Hong SJ, Shin SJ, Kim DS, Kim NM, So SH, Lee SK, Kim EC, Chae SW, Chae HJ: Effect of ginseng mixture on osteoporosis in ovariectomized rats. Immunopharmacol Immunotoxicol 2008, 30:333-345.

21. Zhang Y, Lai WP, Leung PC, Wu CF, Wong MS: Short- to mid-term effects of ovariectomy on bone turnover, bone mass and bone strength in rats. Biol Pharm Bull 2007, 30:898-903.

22. Chen WF, Wong MS: Genistein modulates the effects of parathyroid hormone in human osteoblastic SaOS-2 cells. Br J Nutr 2006, 95:1039-1047.

23. Bhargavan B, Gautam AK, Singh D, Kumar A, Chaurasia S, Tyagi AM, Yadav DK, Mishra JS, Singh AB, Sanyal S, Goel A, Maurya R, Chattopadhyay N: Methoxylated isoflavones, cajanin and isoformononetin, have nonestrogenic bone forming effect via differential mitogen activated protein kinase (MAPK) signaling. J Cell Biochem 2009, 1:388-399.

24. Takahashi N, Yamada H, Yosiki S, Roodman GD, Mundy GR, Jones SJ, Boyde A, Suda T: Osteoclast-like cell formation and its regulation by osteotropic hormones in mouse bone marrow cultures. Endocrinology 1998, 122:1373-1382.

25. Katagiri T, Yamaguchi A, Ikeda T, Yoshiki S, Wozney JM, Rosen V, Wang EA Tanaka H, Omura S, Suda T: The non-osteogenic mouse pluripotent cell line, $\mathrm{C} 3 \mathrm{H} 10 \mathrm{~T} 1 / 2$, is induced to differentiate into osteoblastic cells by recombinant human bone morphogenetic protein-2. Biochem Biophys Res Commun 1990, 172:295-299.

26. Yamaguchi A, Katagiri T, Ikeda T, Wozney JM, Rosen V, Wang EA, Kahn AJ, Suda T, Yoshiki S: Recombinant human bone morphogenetic protein-2 stimulates osteoblastic maturation and inhibits myogenic differentiation in vitro. J Cell Biol 1991, 113:681-687.

27. Hohenhaus MH, McGarry KA, Col NF: Hormone therapy for the prevention of bone loss in menopausal women with osteopenia: is it a viable option? Drugs 2007, 67:2311-2321.

28. Levine JP: Effective strategies to identify postmenopausal women at risk for osteoporosis. Geriatrics 2007, 62:22-30

29. Frolik CA, Bryant HU, Black EC, Magee DE, Chandrasekhar S: Timedependent changes in biochemical bone markers and serum cholesterol in ovariectomized rats: effects of raloxifene $\mathrm{HCl}$, tamoxifen, estrogen, and alendronate. Bone 1996, 18:621-627.

30. Sato M, Bryant HU, Iversen P, Helterbrand J, Smietana F, Bemis K, Higgs R, Turner CH, Owan I, Takano Y, Burr DB: Advantages of raloxifene over alendronate or estrogen on nonreproductive and reproductive tissues in the long-term dosing of ovariectomized rats. J Pharmacol Exp Ther 1996, 279:298-305.

31. Cano A, Dapía S, Noguera I, Pineda B, Hermenegildo C, del Val R, Caeiro JR, García-Pérez MA: Comparative effects of 17beta-estradiol, raloxifene and genistein on bone 3D microarchitecture and volumetric bone mineral density in the ovariectomized mice. Osteoporos Int 2008, 19:793-800.

32. Bahlous A, Kalai E, Hadj Salah M, Bouzid K, Zerelli L: Biochemical markers of bone remodeling: recent data of their applications in managing postmenopausal osteoporosis. Tunis Med 2006, 84:751-757.

33. Owen TA, Aronow MS, Barone LM, Bettencourt B, Stein GS, Lian JB: Pleiotropic effects of vitamin D on osteoblast gene expression are related to the proliferative and differentiated state of the bone cell phenotype: dependency upon basal levels of gene expression, duration of exposure, and bone matrix competency in normal rat osteoblast cultures. Endocrinology 1991, 128:1496-1504.

34. Stein GS, Lian JB: Molecular mechanisms mediating proliferation/ differentiation interrelationships during progressive development of the osteoblast phenotype. Endocr Rev 1993, 14:424-442.

35. Suda K, Woo J-T, Takami M, Sexton PM, Nagai K: Lipopolysaccharide supports survival and fusion of preosteoclasts independent of TNF-a, IL-1, and RANKL. J Cell Physiol 2002, 190:101-108.

36. Yasuda H, Shima N, Nakagawa N, Mochizuki SI, Yano K, Fujise N, Sato Y, Goto M, Yamaguchi K, Kuriyama M, Kanno T, Murakami A, Tsuda E, Morinaga T, Higashio K: Identity of osteoclastogenesis inhibitory factor (OCIF) and osteoprotegerin (OPG): amechanism by which OPG/OCIF inhibits osteoclastogenesis in vitro. Endocrinology 1998, 139:1329-1337.

37. Teitelbaum SL: Osteoclasts, integrins, and osteoporosis. J Bone Miner Metab 2000, 18:344-349.

38. Bord S, Ireland DC, Beavan SR, Compston JE: The effects of estrogen on osteoprotegerin, RANKL, and estrogen receptor expression in human osteoblasts. Bone 2003, 32:136-141.

39. Hu Y, Chan E, Wang SX, Li B: Activation of p38 mitogen-activated protein kinase is equired for osteoblast differentiation. Endocrinology 2003, 144:2068-2074.

40. Jadlowiec J, Koch H, Zhang X, Campbell PG, Seyedain M, Sfeir C: Phosphophoryn regulates the gene expression and differentiation of NIH3T3, MC3T3-E1, and human mesenchymal stem cells via the integrin/ MAPK signaling pathway. J Biol Chem 2004, 17:53323-53330.

41. Ross FP, Teitelbaum SL: Alphavbeta3 and macrophage colony-stimulating factor: partners in osteoclast biology. Immunol Rev 2005, 208:88-105.

42. Takayanagi H, Sato K, Takaoka A, Taniguchi T: Interplay between interferon and other cytokine systems in bone metabolism. Immunol Rev 2005 208:181-193.

43. Khosla S: Minireview: the OPG/RANKL/RANK system. Endocrinology 2001, 142:5050-5055.

\section{doi:10.1186/1472-6882-14-184}

Cite this article as: Chung et al.: Effects of JSOG-6 on protection against bone loss in ovariectomized mice through regulation of osteoblast differentiation and osteoclast formation. BMC Complementary and Alternative Medicine 2014 14:184

\section{Submit your next manuscript to BioMed Central and take full advantage of:}

- Convenient online submission

- Thorough peer review

- No space constraints or color figure charges

- Immediate publication on acceptance

- Inclusion in PubMed, CAS, Scopus and Google Scholar

- Research which is freely available for redistribution 